\title{
Análise da compreensão de licenciandos em Matemática sobre o ensino via resolução de problemas
}

\author{
Analysis of understanding of undergraduate in Mathematics on teaching via \\ problem solving
}

\author{
Luiz Otavio Rodrigues Mendes \\ Érika Janine Maia Afonso \\ Marcelo Carlos de Proença
}

\begin{abstract}
Resumo: 0 objetivo do artigo foi analisar a compreensão de licenciandos em Matemática para abordar, em sala de aula, o ensino-aprendizagem de Matemática via resolução de problemas. Realizamos um estudo descritivo, de natureza qualitativa, em que 18 licenciandos que estavam matriculados no quarto ano do curso de Licenciatura em Matemática de uma universidade pública do norte do Paraná participaram de um curso de formação composto por discussões promovidas a partir de aulas teóricas e do desenvolvimento de uma prática baseada nas ações de ensino propostas por Proença (2018). Os resultados mostram que os participantes, no início do curso, desconheciam o ensino via resolução de problemas, indicando apenas se tratar de uso de problemas do cotidiano. Após o curso, os resultados mostram que a ação de escolha do problema a ser introduzido nesse ensino foi considerada a mais importante, seguida da ação que implica 0 auxílio do professor aos alunos quando tentam resolver o problema.
\end{abstract}

Palavras-chave: Formação Inicial. Matemática. Ensino. Resolução de Problemas.

Abstract: The aim of the article was to analyze the understanding of undergraduate students in Mathematics to approach, in the classroom, the teaching-learning of Mathematics via problem solving. We carried out a descriptive study of a qualitative nature in which 18 undergraduate students who were enrolled in the fourth year of the course Degree in Mathematics at a public university in northern Paraná participated in a training course consisting of discussions promoted from theoretical classes and the development of a practice based on the teaching actions proposed by Proença (2018). The results showed that the participants, at the beginning of the course, were unaware of teaching via problem solving, indicating only the use of everyday problems. After the course, the results showed that the action of choice of problem to be introduced in this teaching was considered the most important, followed by the action that implies the help of the teacher to the students when they try to solve the problem.

Keywords: Initial Formation. Mathematics. Teaching. Problem solving.

\section{Introdução}

Os Parâmetros Curriculares Nacionais de Matemática - PCN (BRASIL, 1998) apresentavam como umas das indicações estratégicas
Luiz Otavio Rodrigues Mendes Doutorando em Educação Para a Ciência e 0 Ensino de Matemática pela Universidade Estadual de Maringá (UEM). Paraná, Brasil.

(iD) orcid.org/0000-0002-3160-8532

$\triangle$ mendesluizotavio@hotmail.com

Érika Janine Maia Afonso Doutoranda em Educação Para a Ciência e o Ensino de Matemática pela Universidade Estadual de Maringá (UEM). Professora da Faculdade de Engenharia e Inovação Técnico Profissional (FEITEP). Paraná, Brasil.

(iD) orcid.org/0000-0003-1850-3434 $\triangle$ erikajaninemaia@gmail.com

Marcelo Carlos de Proença Doutor em Educação para a Ciência. Professor do Programa de Pós-Graduação em Educação Para a Ciência e o Ensino de Matemática da Universidade Estadual de Maringá (UEM). Paraná, Brasil. iD orcid.org/0000-0002-6496-4912 $\bowtie$ mcproenca@uem.br

Recebido em 20/01/2020 Aceito em 03/03/2020 Publicado em 09/04/2020 
ao ensino de Matemática o trabalho por meio da resolução de problemas, evidenciando que 0 problema deve ser o ponto de partida e não a definição. Com a atual Base Nacional Comum Curricular - BNCC (BRASIL, 2017, 2018), esse trabalho foi enfatizado com maior destaque, pois nesses documentos indica-se que uma das habilidades a serem desenvolvidas ao longo da Educação Básica são aquelas voltadas a resolver problemas.

A literatura sobre como abordar a resolução de problemas em sala de aula destaca, assim como já incentivado pelos PCN, que o caminho para introduzir um conteúdo deveria ser por meio de um problema (SCHROEDER e LESTER JR., 1989; ALLEVATO e ONUCHIC, 2014; PROENÇA, 2018). Os autores Schroeder e Lester Júnior (1989) denominaram que o uso do problema como ponto de partida corresponde ao ensinar via resolução de problemas. Proença (2018) utilizou dessa denominação para elencar ações que o professor deveria adotar em sala de aula quando segue o que denominou de ensino-aprendizagem de Matemática via resolução de problemas.

No que se refere, assim, à formação de professores, estudos envolvendo a etapa de formação inicial de futuros professores de Matemática mostraram que quando se oferece uma formação sobre o ensino via resolução de problemas, apesar das dificuldades, os estudantes conseguem ampliar ou construir conhecimentos a respeito do uso do problema como ponto de partida. O estudo de Moço (2013) mostrou que os 10 licenciandos investigados, participantes do Programa Institucional de Bolsa de Iniciação à Docência (PIBID), relataram ser difícil ensinar a partir de problemas matemáticos porque tiveram dificuldades para abordar os conteúdos de forma contextualizada, além de dificuldades para coordenar e orientar os alunos em seus equívocos. Porém, ao permitir que esses licenciandos elaborassem e implementassem suas propostas em sala de aula, a formação oferecida ajudou-Ihes a entender ser necessário conhecer muito bem o conteúdo a ser trabalhado para que com isso possam valorizar o que os alunos fazem quando se envolvem na construção de problemas. Na pesquisa de Raiva, Moraes e Borges (2015), a investigação sobre como professores em formação inicial refletem a respeito do desafio de analisar e elaborar problemas para os alunos, mostrou que a escolha de bons problemas foi considerada como um desafio para a sua prática de ensino, concluindo-se que trabalhar o ensino via resolução de problemas ainda é um desafio nos processos de ensino e de aprendizagem, sendo necessário possibilitar que esses estudantes vivenciem mais esse ensino antes de se tornarem professores.

No estudo de Proença (2016a), foi identificado que licenciandos de uma turma do quarto ano do curso tiveram dificuldades para compreender o problema Torre da Hanói, adotado como 
ponto de partida, porque revelaram não entender qual seria a haste final a posicionar os discos e porque realizaram movimentos desnecessários dos discos. No entanto, foi possível favorecer-lhes conhecimentos para exercer o ensino via resolução de problemas. Em outro estudo realizado por Proença (2016b), apesar dos quatro licenciandos em Matemática apresentarem, no início da formação recebida, dificuldades para encontrarem estratégias de resolução dos problemas propostos, revelou entendimento desses estudantes de que o uso do problema como ponto de partida é importante e que se deve valorizar as estratégias dos alunos, sendo necessário, ao planejar aulas, prever as possíveis estratégias de resolução do problema.

Diante dessas considerações, entendemos que aprender sobre a resolução de problemas deve ser foco na formação inicial de professores, justamente porque tem potencial para levar os alunos a ampliarem seus conhecimentos para compreender Matemática e para aprender a resolver problemas que envolvem conteúdos matemáticos. Dessa forma, tivemos como objetivo, neste artigo, analisar a compreensão de licenciandos em Matemática para abordarem, em sala de aula, ensino-aprendizagem de Matemática via resolução de problemas.

Esta pesquisa tem por primazia trabalhar com a formação inicial de professores de Matemática e a resolução de problemas como ponto de partida, acometendo-os como objeto de estudo, conforme percebemos na literatura resultados profícuos pelos trabalhos que trilharam este caminho (MOÇO, 2013; RAIVA, MORAES e BORGES, 2015; PROENÇA. 2016a). No entanto, este estudo se difere dos já supracitados por abordar a perspectiva de Proença (2018) sobre o ensinoaprendizagem via resolução de problemas, bem como por propormos procedimentos metodológicos que tangenciam a Teoria da Representações Sociais com base nos estudos de Abric (1998) e Jodelet (2004) e a utilização do software IraMuTeQ para auxílio nas análises, proporcionando, respectivamente, uma visão de uma perspectiva diferente e uma maior rigorosidade nas análises.

Isto posto, organizamos este trabalho em cinco seções. A introdução constituiu a primeira. Por conseguinte, abordamos o ensino-aprendizagem de Matemática via resolução de problemas. Compondo a terceira, quarta e quinta seções, respectivamente, apresentamos os procedimentos metodológicos, a análise dos nossos dados e as considerações finais, destacando os resultados encontrados neste estudo. 


\section{0 ensino-aprendizagem de Matemática via resolução de problemas em sala de aula}

Dentre as abordagens de ensino que podem ser utilizadas em sala de aula para desenvolver os conteúdos/conceitos/assuntos matemáticos, destacamos aquela que foi denominada por Schroeder e Lester Júnior (1989) como ensinar via resolução de problemas. Esta abordagem de ensino, indicada pelos autores como a mais adequada, apresenta o problema como ponto de partida da atividade que será realizada, e possibilita que os alunos possam estabelecer relações entre as ideias matemáticas, os contextos diferentes e os problemas propostos. Do mesmo modo, tal abordagem contribui para que sejam construídos os conceitos/ideias/métodos matemáticos pelos alunos durante a resolução de um problema e que só depois esses assuntos sejam formalizados em sala de aula pelo professor. Nesta abordagem de ensino, Fiorentini (2011, p. 3) destacou que "[...] a ênfase recai sobre o aluno e os processos da aprendizagem e da resolução de problemas, apostando na capacidade e criatividade do aluno desenvolver/fazer matemática".

Além disso, na literatura, é possível nos depararmos com diversos pesquisadores que realizaram estudos relacionados às abordagens de ensino que podem ser utilizadas para ensinar Matemática com a resolução de problemas em sala de aula, ao que é um problema, a quais são as fases/etapas para solucionar um problema e aos procedimentos e conhecimentos mobilizados pelo solucionador do problema (SCHROEDER e LESTER JR., 1989; MAYER, 1992; POLYA, 1994; ECHEVERRÍA, 1998; STERNBERG, 2000; BRITO, 2010; SERRAZINA, 2017; VALE, 2017). Diante disso, no que se refere às formas de se abordar a resolução de problemas em sala de aula, verificamos apontamentos/direcionamentos de alguns autores que indicaram sobre como devem ocorrer efetivamente as ações para o ensino da Matemática em sala de aula utilizando a resolução de problemas como uma abordagem de ensino como, por exemplo, os de Proença (2018).

Dessa forma, ao considerar/caracterizar o ensino-aprendizagem de Matemática via resolução de problemas, e pensando nos encaminhamentos para esse ensino e a aprendizagem de Matemática em sala de aula, Proença (2018) elaborou uma sequência composta por cinco ações que estruturam uma abordagem didática e que devem ser realizadas em sala de aula antes de se iniciar o estudo de um determinado conteúdo/conceito/assunto da matemática, a saber: 1) Escolha do problema; 2) Introdução do problema; 3) Auxílio aos alunos durante a resolução; 4) Discussão das estratégias dos alunos; e 5) Articulação das estratégias dos alunos ao conteúdo.

O ponto de partida dessa sequência de ações é a escolha do problema, que segundo 
Proença (2018) caracteriza-se pelo momento em que o professor deverá escolher a situação matemática que será utilizada de modo que ela seja reconhecida como um problema para os alunos participantes da atividade, pois quando os alunos fazem esse reconhecimento da situação proposta como um problema, ao buscar resolvê-la, eles podem desenvolver um processo de pensamento baseado em etapas de resolução (PROENÇA, 2019). Assim, segundo Proença (2018, p. 17), "uma situação de Matemática se torna um problema quando a pessoa precisa mobilizar conceitos, princípios e procedimentos matemáticos aprendidos anteriormente para chegar a uma resposta". Nesta mesma perspectiva, Echeverría (1998) apontou que uma situação se configura como um problema quando o aluno se depara com alguma dificuldade que o obrigue a questionar-se sobre qual seria o caminho que ele precisará seguir para alcançar a meta (a solução).

Para tanto, neste momento inicial de escolha de uma situação — o possível problema -, é preciso que o professor: a) leve em consideração os conhecimentos prévios dos alunos referentes aos conceitos que serão utilizados para solucionar a situação; b) escolha uma situação que permita a construção de um novo conceito e proporcione condições para que 0 aluno possa fazer relações entre os conceitos prévios e o novo conceito proposto a partir da solução do problema selecionado. Além disso, Proença (2018) destacou que o problema escolhido pelo professor deve ser possível de ser solucionado por diversas estratégias e/ou apresentar várias respostas, e que essas estratégias de resolução e respostas devem ser previstas pelo professor antes da aplicação da atividade.

Já na introdução do problema, segunda ação proposta por Proença (2018), é o momento em que o professor, em sala de aula, passa a ter o contato efetivo com o aluno para apresentar a situação matemática e iniciar a aplicação de sua proposta de ensino-aprendizagem de Matemática via resolução de problemas que foi elaborada previamente. Segundo o autor, nesta ação, os alunos podem ser divididos em grupos para que tenham a oportunidade de compartilhar seus conhecimentos prévios e elaborar estratégias que possam solucionar a situação matemática que neste momento, já pode ter se configurado com um problema para os solucionadores. Destacamos que esta ação mostra a importância da elaboração prévia e análise da escolha do problema que será trabalhado, pois os problemas devem ser difíceis, porém passíveis de serem solucionados para que os participantes não se sintam desmotivados e desistam de encontrar as possíveis soluções. 
A terceira ação, auxílio aos alunos durante a resolução, é o momento em que o professor deve transitar entre os grupos buscando direcionar os alunos na resolução da situação, e auxiliando nas dificuldades que surgirem no desenvolvimento do processo, assumindo assim um papel de "observador, incentivador e direcionador da aprendizagem, apoiando os alunos a desenvolver autonomia frente ao processo de resolução" (PROENÇA, 2018, p. 51).

$\mathrm{Na}$ quarta ação, discussão das estratégias dos alunos, promove-se uma socialização de ideias entre os grupos para que todos possam expor suas estratégias e discuti-las. Segundo Proença (2018), uma sugestão para este momento é que os alunos apresentem suas propostas na lousa para que possam fazer uma avaliação das possíveis repostas apresentadas. Nesta socialização, será possível identificar as dificuldades que os alunos tiveram no que diz respeito às etapas de resolução de problemas - representação, planejamento, execução, monitoramento.

A respeito dessas quatro etapas de resolução de problemas, Brito (2010) destacou que na representação é requisitado ao solucionador a compreensão verbal da proposição, a fim de que ele possa compreender a natureza matemática da situação que the foi apresentada por escrito. Já no planejamento, o solucionador deverá criar e elaborar um plano para que consiga, a partir dele, obter uma solução para a situação proposta. Assim, será necessário organizar estrategicamente a informação buscando uma representação que auxilie a realizar da melhor forma a estratégia obtida. Em seguida, com base em uma ação procedimental em cálculos, desenhos e outras formas de representações, o solucionador irá realizar a estratégia previamente elaborada na etapa do planejamento. Finalmente, na etapa do "monitoramento", o solucionador deverá avaliar a solução obtida, se ela está coerente com a situação proposta e validar todo 0 processo de solução que foi construído.

Já na última ação de ensino proposta por Proença (2018), busca-se a articulação das estratégias dos alunos ao conteúdo, ou seja, articular as estratégias elaboradas pelos alunos ao conteúdo/conceito/assunto que se quer ensinar, de modo que seja possível "apresentar uma nova resolução aos alunos, envolvendo o conteúdo, o que teria como base uma justificativa permeada por essa articulação" (PROENÇA, 2019, p. 8). Vale ressaltar que em alguns casos, nessa condução da quinta ação, pode ocorrer de não ser possível realizar a articulação. Diante disso, o autor sugeriu que o professor pode apresentar a resolução do problema de forma direta aos alunos com o uso do novo conteúdo, ou seja, pode realizar a formalização desejada.

Para Proença (2019, p. 15), essas ações de ensino são consideradas como importantes 
pois "valorizam os conhecimentos prévios dos alunos quando se aborda uma situação de Matemática como ponto de partida (possível problema), o que favorece a análise, pelo professor, das dificuldades de seus alunos no processo de resolução de problemas". Dessa forma, é possível verificar a necessidade de um planejamento sobre as ações que serão desenvolvidas ao decorrer do processo quando um professor inicia um trabalho em sala de aula que envolve o ensinoaprendizagem de Matemática via resolução de problemas.

\section{Procedimentos Metodológicos}

Este estudo classifica-se como descritivo. Para Gil (2008, p. 28) "as pesquisas deste tipo têm como objetivo primordial a descrição das características de determinada população ou fenômeno ou o estabelecimento de relações entre variáveis". Assim, neste artigo, pretendemos descrever as características de futuros professores a respeito de suas compreensões sobre 0 ensino de Matemática via resolução de problemas. Diante disso, o delineamento deste estudo é de natureza quantitativa e qualitativa. Souza e Kerbauy (2017, p. 34) destacam sobre estas abordagens ao apontarem que "a primeira, como abordagem que recorre a estatística para explicação dos dados e a segunda que lida com interpretações das realidades sociais", uma vez que, utilizamos análises estatísticas, mas acreditamos que elas corroboram ao nosso interesse em como os participantes dão significado ao ensino.

Uma universidade pública no norte do estado do Paraná constituiu-se como lócus de estudo. Os participantes foram 18 futuros professores que estavam no $7^{\circ}$ semestre (quarto ano) do curso de Licenciatura em Matemática. Para o desenvolvimento da pesquisa realizamos um curso de formação durante quatro semanas totalizando 8 horas-aulas, sendo 2 h/a estudando a parte teórica e as outras 6 h/a desenvolvendo uma prática com base nas ações de Proença (2018). O cronograma das atividades desenvolvidas é apresentado no Quadro 1.

Quadro 1: Cronograma de atividades no curso de formação

\begin{tabular}{|c|l|}
\hline $\begin{array}{c}\text { Semana e carga } \\
\text { horária }\end{array}$ & \multicolumn{1}{|c|}{ Descrição da atividade } \\
\hline $\begin{array}{c}1^{\text {a }} \text { semana }-2 \\
\text { h/a }\end{array}$ & $\begin{array}{l}\text { Nesta primeira semana foram desenvolvidas atividades de cunho teórico, sendo } \\
\text { trabalhado a literatura sobre a resolução de problemas, bem como estudos de Brito } \\
(2006), \quad \text { Schoenfeld (1992) e Pólya (1994). Além disso, também foram } \\
\text { apresentadas as cinco ações descritas por Proença (2018), conforme já as } \\
\text { destacamos no embasamento teórico deste trabalho. Para tratar e discutir a } \\
\text { utilização das ações, realizamos passo a passo cada uma, abordando o que deve }\end{array}$ \\
\hline
\end{tabular}




\begin{tabular}{|c|c|}
\hline & $\begin{array}{l}\text { ser feito em cada uma com o seguinte problema, envolvendo o conteúdo de } \\
\text { sistemas de equações: } \\
\text { Um quintal há } 36 \text { animais entre porcos e galinhas. Sabe-se que há no todo } 112 \\
\text { pés. Quantos são os porcos e quantas são as galinhas? (adaptado de Proença, } \\
\text { 2018). }\end{array}$ \\
\hline $\begin{array}{c}2^{\mathrm{a}} \text { semana }-2 \\
\mathrm{~h} / \mathrm{a}\end{array}$ & $\begin{array}{l}\text { Na segunda semana, desenvolvemos atividades práticas com os licenciandos } \\
\text { sendo que eles em duplas deveriam elaborar, com base em livros didáticos, uma } \\
\text { proposta para aplicação de um conteúdo de sua preferência com as cinco ações } \\
\text { descritas por Proença (2018). Nesta semana os estudantes conseguiram realizar } \\
\text { a ação de escolha do problema. }\end{array}$ \\
\hline $\begin{array}{c}3^{\mathrm{a}} \text { semana }-2 \\
\mathrm{~h} / \mathrm{a}\end{array}$ & $\begin{array}{l}\mathrm{Na} \text { terceira semana os estudantes deram continuidade no desenvolvimento das } \\
\text { propostas, realizando outras três ações: introdução do problema, auxilio aos } \\
\text { alunos durante a resolução, discussão das estratégias. }\end{array}$ \\
\hline $\begin{array}{c}4^{\mathrm{a}} \text { semana }-2 \\
\mathrm{~h} / \mathrm{a}\end{array}$ & $\begin{array}{l}\text { Por fim, na última semana os futuros professores finalizaram a proposta fazendo a } \\
\text { ação de articulação da estratégia ao conteúdo. Além disso, eles apresentaram suas } \\
\text { propostas para os outros colegas. Para finalizar foi realizado um feedback sobre } \\
\text { todo o processo. }\end{array}$ \\
\hline
\end{tabular}

Fonte: Elaboração dos Autores

A coleta de dados se deu por meio de dois questionários, um primeiro, de caráter diagnóstico, entregue na primeira semana do curso antes de começar todas as atividades, ou seja, no primeiro contato com os estudantes, e o segundo, apresentado aos licenciandos no final de todo o curso, ou seja, o último contato. 0 tipo das questões presentes em cada um desses dois instrumentos de coletas de dados e como nós as analisamos são apresentadas a seguir.

O primeiro questionário era composto por duas questões abertas, a saber:

1) Descreva como achar melhor, o que você compreende por ensino de Matemática via resolução de problemas?

2) Explique como você faria para ensinar um conteúdo matemático, de sua escolha, via resolução de problemas?

Para a análise desses dados, utilizamos o software IraMuTeQ para realizar a construção de gráficos de similitudes. Nestes gráficos, é possível identificar as palavras mais coocorrentes e as ligações - chamaremos na análise de $n$ - existentes entre elas. Para essa análise dos dados, os estudantes foram identificados por meio da letra $E$ seguido de um número aleatório que the foi atribuído, como por exemplo, E12 - estudante identificado pelo número 12 -, pois assim além de identificar as ligações, é possível compreender o que ela representa com base nas respostas dos licenciandos. $O$ segundo questionário era composto por 9 assertivas do tipo Likert, como 
mostra o Quadro 2, e uma questão de evocação de palavras.

Quadro 2: Assertivas da questão tipo Likert

a) Considero que não terei dificuldades para ensinar matemática via resolução de problemas quando professor formado.

b) Acredito que posso adotar o ensino de Matemática via resolução de problemas em minha prática docente.

c) Compreendi todo o processo de como se ensina matemática via resolução de problemas.

d) No início achei que seria difícil, mas depois com a discussão teórico-prática ficou fácil entender como ensinar matemática via resolução de problemas.

e) Acredito que posso aplicar no estágio o ensino de matemática via resolução de problemas.

f) Penso que ficou claro para o meu grupo a compreensão de como ensinar via resolução de problemas.

g) Penso que é difícil ensinar via resolução de problemas.

h) Eu recomendaria para colegas de profissão o ensino de matemática via resolução de problemas.

i) Dentre as etapas para ensinar via resolução de problemas, algumas eu não entendi bem.

Fonte: Elaboração dos Autores

Para estas questões, os estudantes poderiam marcar valores de 1 a 5 , seguindo a relação da Tabela 1 que posteriormente foram analisadas com base no Ranking Médio (RM) que calcula a média ponderada de todas as respostas para a assertiva.

Tabela 1: Opções de marcação das assertivas e valor do ranking médio

\begin{tabular}{lccccc}
\hline Opção & Discordo & $\begin{array}{c}\text { Discordo } \\
\text { Parcialmente }\end{array}$ & Não Opino & $\begin{array}{c}\text { Concordo } \\
\text { Parcialmente }\end{array}$ & Concordo \\
\hline Valor & 1 a 1,5 & 1,6 a 2,5 & 2,6 a 3,4 & 3,5 a 4,4 & 4,5 a 5 \\
\hline
\end{tabular}

Fonte: Elaboração dos Autores

Quanto à última questão, foi solicitado aos estudantes o seguinte:

3) Descreva cinco palavras em ordem de importância sobre o que você entende por "ensino de Matemática via resolução de problemas", após justifique a escolha de cada uma das palavras.

As palavras evocadas e explicadas pelos licenciandos foram analisadas com base na teoria das representações sociais criada por Serge Moscovici. Jodelet (2004, p. 22) destaca que essa teoria "é uma forma de conhecimento, socialmente elaborada e partilhada, com um objetivo prática, e que contribui para a construção de uma realidade comum a um conjunto social". Para o desenvolvimento desta análise, criamos um corpus com todas as palavras evocadas em suas 
ordens e utilizamos o programa online Open Evoc para construir o quadro de quatro casas, composto de 4 quadrantes. Destes, o quadrante superior à esquerda apresenta o núcleo central.

Para Abric (1998, p. 33) o núcleo central "é a base comum propriamente social e coletiva que define a homogeneidade de um grupo, através de seus comportamentos individualizados que podem parecer contraditórios". Nesse sentido, as palavras compreendidas neste quadrante apresentam as representações sociais dos licenciandos. Desse modo, submetemos o corpus ao software IraMuTeQ para criar análises de similitude, a fim de visualizar as ligações entre as palavras. Desta forma, é possível compreender as representações sociais dos licenciandos a partir das explicações destas palavras.

\section{Análise dos dados}

\subsection{A compreensão prévia dos licenciandos sobre o ensino de Matemática via resolução} de problemas

Com os dados advindos do primeiro questionário, referente a primeira questão, foi elaborado um gráfico de similitude com o software IraMuTeQ, que está representado na Figura 1.

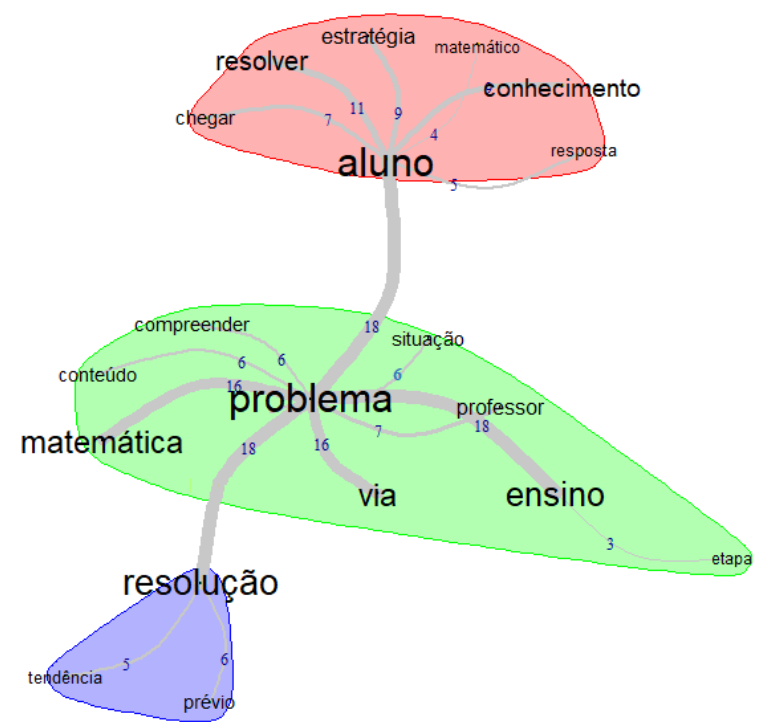

Figura 1: Compreensão inicial dos licenciandos sobre o ensino de Matemática via resolução e problemas (Elaboração dos Autores)

É possível perceber na Figura 1 três agrupamentos de cores diferentes, que denominamos como categorias com base nas palavras de maior expressividade, sendo: aluno (vermelho), problema (verde) e resolução (azul). Nesta última, podemos evidenciar duas ligações, da palavra principal - resolução - com as palavras tendência $(n=5$, sendo o $n$ o número de ligações entre 
estas duas palavras) e prévio $(n=6)$. Quanto à palavra tendência, sua ligação com a resolução de problemas advém das seguintes falas: E11 - 0 ensino de Matemática via resolução de problemas é uma alternativa e uma tendência no ensino de Matemática; E17 - 0 ensino de Matemática via resolução de problemas é uma das tendências do ensino de Matemática; E18 O ensino de -atemática via resolução de problemas é uma tendência da Educação Matemática.

Com base nestas falas, observamos que estão em conformidade às recomendações presentes no documento das Diretrizes Curriculares da Educação Básica do Estado do Paraná (PARANÁ, 2008) que trata a resolução de problemas como uma tendência metodológica para 0 ensino da Matemática. Já quanto à palavra prévio, entendemos que ela está ligada a conhecimentos, e nesse sentido, é necessário os conhecimentos prévios dos alunos para se realizar a resolução como retrata E9 - "Compreendo o ensino de Matemática via resolução de problemas como uma situação proposta aos alunos, visando que eles resolvam com o auxílio dos seus conhecimentos prévios".

Voltando-se à palavra resolução evidenciamos na Figura 1 uma forte ligação $(n=18)$ com problema. É possível notar nesta categoria - em verde —, que as ligações mais expressivas também ocorrem da palavra problema com ensino $(n=18)$, Matemática $(n=16)$ e via $(n=16)$ justamente pelos alunos explicitarem em suas respostas a frase o ensino de Matemática via resolução de problemas, sendo que as proposições não aparecem no gráfico de similitude. Além destas ligações, também encontram-se nesta categoria relações com as palavras professor $(n=$ 7) e situação $(n=6)$. Evidenciamos essa relação nas respostas dos estudantes, sendo que há uma compreensão de que o professor deve promover situações problema aos alunos como é reforçado por E10 - "De acordo com os conhecimentos prévios, o professor pode propor a situação obedecendo as três fases, antes, durante e depois", que além disso destaca que deve ocorrer em fases.

Ainda nesta categoria, encontra-se uma relação entre as palavras compreender ( $n=6)$ e conteúdo $(\mathrm{n}=6)$. Essa relação tem o sentido de que, com a abordagem via resolução de problemas, é possível que o aluno consiga compreender o conteúdo como destaca E2 - "O ensino de Matemática via resolução de problemas seria para trabalhar os conteúdos matemáticos, de maneira que 0 aluno possa compreender".

A última categoria - em vermelho - aponta a relação entre problema e a palavra aluno $(n=18)$. Pode-se perceber que para os licenciandos o ensino via resolução de problemas está 
voltado para o aluno, além disso os termos conhecimento $(n=10)$, resolver $(n=11)$ e Matemática $(n=4)$ reforçam a ideia de se trabalhar os conhecimentos prévios sobre a Matemática dos alunos para resolver as situações problema como aponta as seguintes falas:

E3 - Este problema deve envolver situações reais do dia a dia, no qual o aluno vai utilizar seus conhecimentos prévios para resolver o problema.

E5 - A ideia é que os alunos consigam enxergar padrões e criar conexões entre 0 conhecimento que eles já têm, de modo que seja possível que os alunos resolvam uma situação

E13 - O ensino de matemática via resolução de problemas trabalha conteúdos matemáticos de uma forma contextualizada em que é entregue um problema matemático ao aluno e através dos seus conhecimentos prévios, ele deve chegar a uma solução.

Neste sentido, percebemos que para os licenciandos, o ensino via deve ser centrado nos alunos trabalhando seus conhecimentos prévios, conforme apontam as falas. Por fim, a última relação diz respeito aos termos estratégia $(n=9)$, chegar $(n=7)$ e resposta $(n=5)$ que se refere, na visão dos estudantes, que os alunos devem utilizar-se de estratégias para chegar nas respostas, como aponta a fala deste estudante:

E8 - 0 ensino de Matemática via resolução de problemas procura trabalhar um conteúdo através de uma situação contextualizada ou uma prática, em que os alunos partem de um encaminhamento inicial, desenvolvendo estratégias para chegar a uma resposta coerente e desejada. As estratégias podem se diferenciar de um aluno para outro, pois não há um caminho exato a ser seguido para chegar ao resultado.

Desta forma, percebemos que há um cuidado por parte dos estudantes de levar em consideração as várias possíveis soluções dos alunos, reforçando assim como o centro do processo. Com base nestas respostas dos estudantes, evidenciamos que a compreensão prévia deles sobre o que é o ensino via resolução de problemas está atrelada como uma tendência metodológica, indo ao encontro do que está proposto nas Diretrizes Curriculares da Educação Básica do Estado do Paraná (2008). Consideram também que o aluno é o centro do processo, devendo-se levar em conta seus conhecimentos prévios e as várias soluções desenvolvidas por estes e que o professor deve trazer situações, se possível cotidianas, facilitando assim que o aluno possa compreender o conteúdo matemático trabalhado. Dessa forma, percebemos ideias gerais e de forma superficial sem uma sequência para se trabalhar o ensino via resolução de problemas como propôs Proença (2018), mostrando que os alunos não tinham conhecimento sobre esta abordagem. 
Este entendimento ficou mais claro quando solicitamos na pergunta 2 que eles explicassem um exemplo de como ensinariam um conteúdo, de sua escolha, com base no ensino via resolução de problemas. Os conteúdos que foram citados apenas uma única vez pelos estudantes foram sete, a saber: volume do cubo, equação, razão e proporção, regra de três, frações, completar quadrados e sistemas de equações. Para os outros onze licenciandos (61 \%), todos citaram o conteúdo de função afim.

É interessante que para estes estudantes os exemplos buscaram retratar situações cotidianas, como pode ser observado nas respostas a seguir:

E2 - Por exemplo, para ensinar função, eu buscaria um problema relacionado ao tema e, também, com o cotidiano ou o dia a dia do aluno, seja em seu contexto social, cultural, entre outros. Após isso, seria discutido com os alunos sobre o problema e eu auxiliaria os alunos de forma com que eles fossem capazes de interpretar o problema, buscando estratégias para a resolução do problema.

E12 - Eu utilizaria a resolução de problemas para introduzir um conteúdo matemático, como por exemplo o conceito de função afim. Neste caso, colocaria uma situação prática do dia a dia, ou algo que os alunos pudessem perceber padrões e regularidades.

E16 - Para iniciar o conteúdo de função, podemos solicitar aos alunos que tragam a sua conta de água e perguntar como encontramos a relação entre o consumo de água e o valor pago. Como podemos expressar isso matematicamente. 0 mesmo pode ser feito para conta de energia elétrica.

Estas respostas confirmam que eles não haviam trabalhado com esta abordagem até aquele momento, visto que para os estudantes a abordagem do ensino via resolução de problemas, deve ocorrer a partir de situações cotidianas, sem fases para seu desenvolvimento. Após este questionário foi realizado o curso de formação como foi destacado no Quadro 1.

\subsection{A compreensão dos licenciandos após a formação sobre o ensino de Matemática via resolução de problemas}

Após o curso, foi entregue o segundo questionário, com objetivo de evidenciar qual a compreensão dos licenciandos sobre o ensino via resolução de problemas. Para tanto, por meio de assertivas tipo Likert de cinco pontos, buscamos contrastar a opinião dos alunos sobre o que eles compreendiam em relação a três eixos: possíveis dificuldades quanto à proposta de Proença (2018) - relacionado as assertivas a, d e g do Quadro 2 - a adoção da proposta em sua prática — relacionado as assertivas b, e e $\mathrm{h}$ do Quadro 2 - e a compreensão das ações de forma geral - relacionado as assertivas c, f e j do Quadro 2. Para analisar estas assertivas, utilizamos 0 
gráfico em barras, em que expressamos as respostas de todos os 18 licenciandos em três cores, a saber: azul, laranja e cinza. Outrossim, apresentamos também o Ranking Médio (média ponderada) das respostas que norteiam a compreensão geral dos licenciandos sobre a assertiva. A Figura 2 apresenta as respostas dos estudantes com intuito de investigar se eles tiveram dificuldades em trabalhar o ensino via resolução de problemas. Para analisarmos a Figura 2 observamos primeiramente o Ranking Médio das respostas, fazendo assim uma relação com a Tabela 1. Posteriormente, caso necessário, observamos as respostas no geral.

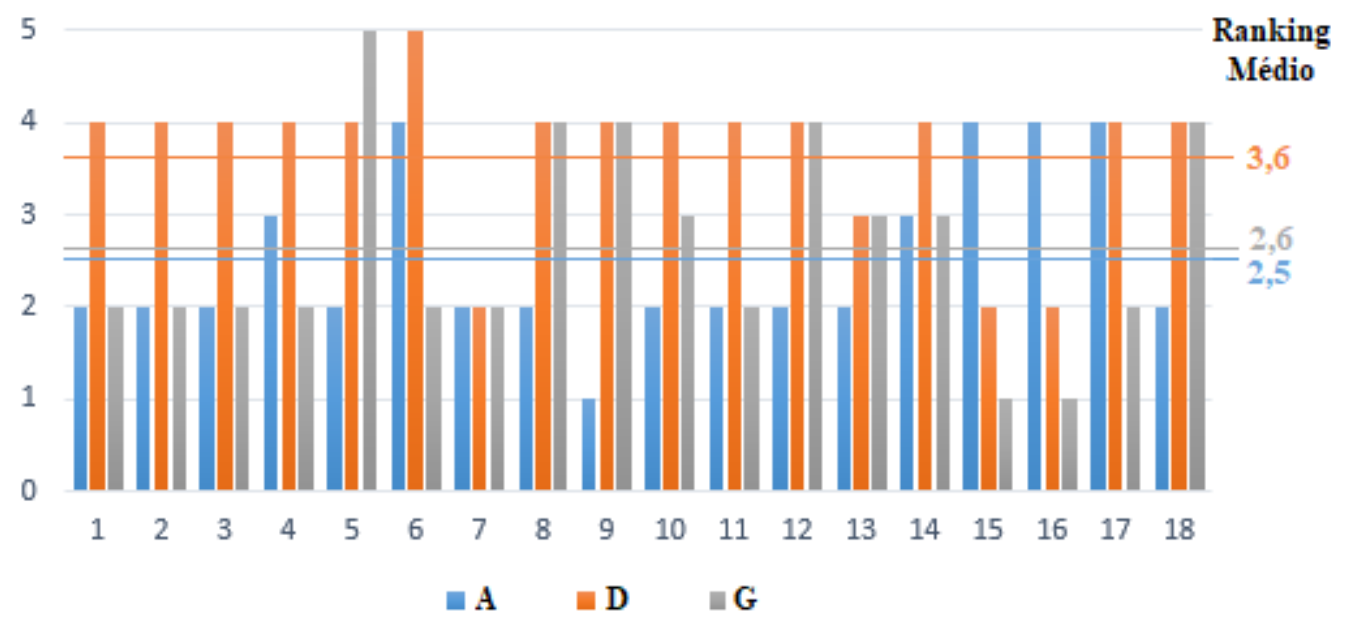

Figura 2: Análise das considerações dos alunos sobre as dificuldades de se ensinar Matemática via resolução de problemas (Elaboração dos Autores)

A assertiva "a" afirmava que não haveria dificuldades em ensinar a abordagem quando fosse professor formado. A resposta dos licenciandos tem uma tendência para opção que eles "discordam parcialmente" sobre essa assertiva. No entanto, ao se observar as marcações dos estudantes, onze $(61,1 \%)$ selecionaram a opção discordo parcialmente. Desta forma, estes licenciandos consideram que podem ter certa dificuldade em ensinar com esta abordagem indo ao encontro dos resultados de Moço (2013).

Em contraste, a assertiva "d" buscou situar se essa dificuldade seria na primeira impressão com a abordagem. As respostas dos licenciandos teve a tendência de concordar parcialmente, apontando que apesar de os alunos considerarem inicialmente que seria difícil trabalhar com a proposta, posteriormente ao desenvolvimento do curso esta percepção foi diminuindo em relação ao questionário final, que será analisado a diante. Destaca-se, assim, que quanto mais os alunos são instruídos a trabalhar com esta abordagem, menores ficam as dificuldades. Raiva, Moraes e Borges (2015) já apontavam também essa necessidade de fazer um trabalho continuo com os licenciandos para um melhor aperfeiçoamento. 
Por fim, a assertiva " $g$ " indagou diretamente se eles teriam dificuldade de ensinar esta abordagem. Os resultados tiveram a tendência a "não opino", favorecendo assim a compreensão que somente com o curso os licenciandos não conseguem ter a noção da real dificuldade, até que coloquem em prática na Educação Básica. Nesse sentido, é possível compreendermos a necessidade de uma formação contínua sobre esta abordagem para que os licenciandos testem as possibilidades e conforme a prática, possuam maiores habilidades de trabalhar com o problema como ponto de partida.

O segundo eixo analisado consistiu em verificar se os licenciandos adotariam a abordagem em sua prática, chegando a recomendá-lo a colegas professores. Os resultados são apresentados na Figura 3.

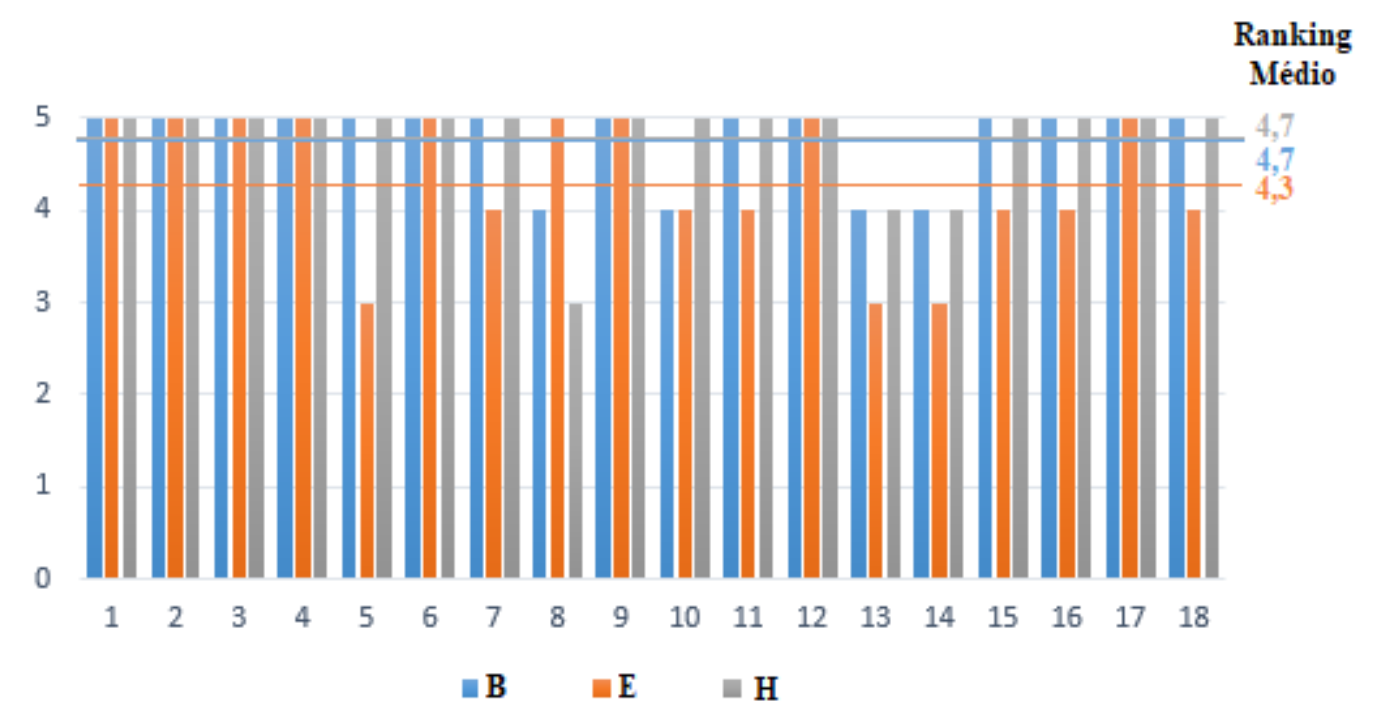

Figura 3: Compreensão dos licenciandos sobre a utilização do ensino de Matemática via resolução de problemas (Elaboração dos Autores)

A primeira assertiva "b" corresponde se os licenciandos adotariam o ensino via resolução de problemas em sua prática docente. Teve como resultado, segundo o ranking médio, o valor de 4,7 , confirmando que eles concordam com a afirmação. Concomitantemente, os resultados da assertiva "e", ao se obter um RM de 4,3, aponta que os estudantes "concordam parcialmente" que inclusive aplicariam a abordagem no Estágio Curricular Supervisionado.

Por fim, a assertiva "h" buscava verificar se eles indicariam a proposta para algum colega professor. Os resultados do Ranking Médio com 4,7 confirmaram esse apontamento. Nesse sentido, é possível compreender segundo a resposta dos licenciandos que não só eles utilizariam o ensino via resolução de problemas, como também utilizariam no Estágio e inclusive indicariam para colegas. Estas respostas se apresentam de forma profícua para utilização da abordagem 
pelos licenciandos.

Por último, destacamos os resultados sobre a compreensão dos estudantes no processo, ou seja, sobre as cinco ações de Proença (2018). Os resultados são apresentados na Figura 4.

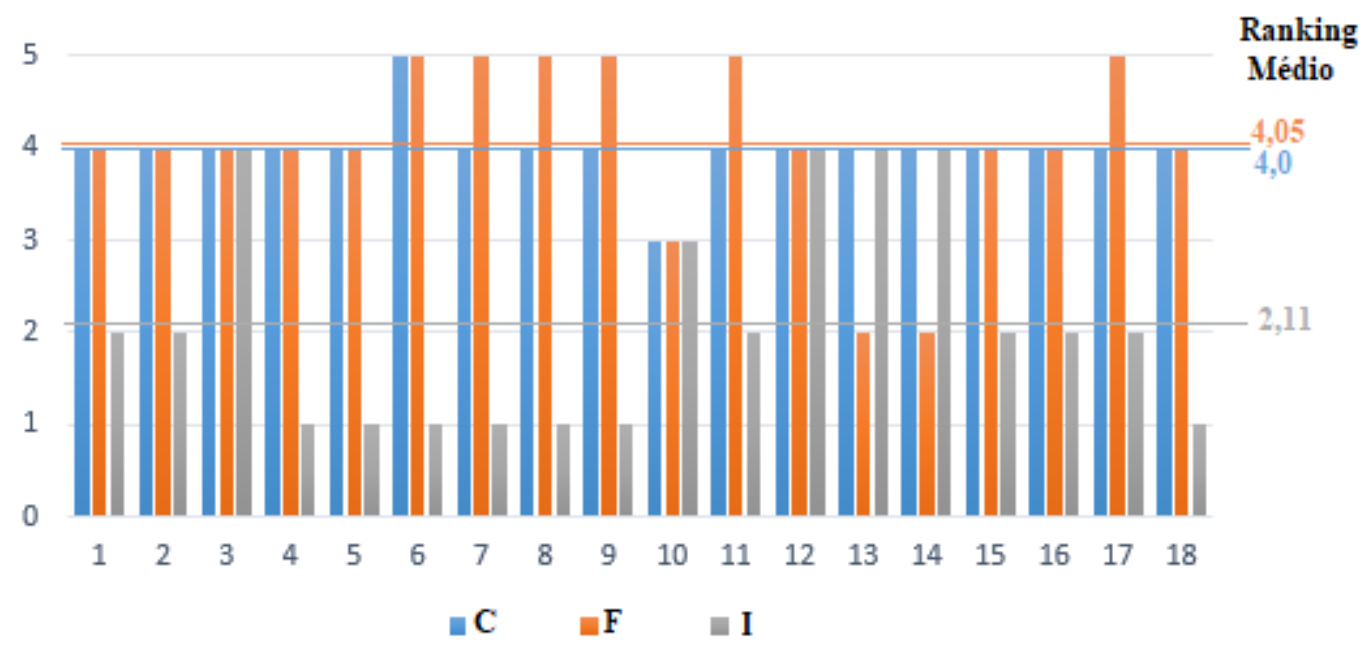

Figura 4: Compreensão dos licenciandos sobre o ensino de Matemática via resolução de problemas (Elaboração dos Autores)

A primeira assertiva "c", diz respeito se os estudantes compreenderam todo o processo de ensino via, ou seja, as cinco ações de Proença (2018). A resposta dos licenciandos, com RM de 4,0, evidencia o fato de que eles concordam parcialmente com essa afirmação. Nesse sentido, compactuamos com a ideia de Raiva, Moraes e Borges (2015) quando acusam reconhecer que "essa metodologia pode ser um processo demorado, mas acredita-se no papel do compartilhamento de boas práticas como forma de colocar mais professores a par de metodologias que possam contribuir com a qualificação se suas aulas" (p. 10). Sendo assim, compreendemos uma oportunidade ímpar aos licenciandos de terem esta abordagem em sua formação, visto que os resultados do questionário prévio mostraram que eles não a conheciam.

Quanto à assertiva "f", também teve a mesma tendência, concordo parcialmente, ao se ter um RM de 4,05 o que reitera o entendimento que apenas o curso não poderia dar todo o suporte para que os estudantes compreendessem o processo. Por fim, a última assertiva "i" aponta que os licenciandos entenderam de forma parcial todas as etapas reforçando assim a necessidade de uma formação contínua, como já havíamos destacado.

Para compreendermos mais especificamente o que eles entenderam de cada etapa de Proença (2018), buscamos verificar por meio de suas representações sociais o que significava 0 ensino via resolução de problemas para eles. Os resultados das cinco palavras elencadas em ordem de importância por eles são apresentados no Quadro 3, no formato de um quadro de quatro 
casas.

Quadro 3: Quadro de quatro casas, apresentando frequência e a ordem de evocação das palavras

\begin{tabular}{|l||l||l|}
\hline \multicolumn{1}{|c||}{+} & \multicolumn{2}{|c|}{ Frequência $>=2.86$ / Ordem de evocação $<\mathbf{3}$} \\
\hline \hline $11.43 \%$ & estratégia & 2.5 \\
\hline \hline $11.43 \%$ & mediação & 2.75 \\
\hline \hline $10 \%$ & problema & 1.86 \\
\hline \hline $7.14 \%$ & resolução & 2.6 \\
\hline \hline $5.71 \%$ & conhecimento & 2 \\
\hline \hline $4.29 \%$ & raciocínio & 2 \\
\hline \hline $2.86 \%$ & compreensão & 1.5 \\
\hline
\end{tabular}

\begin{tabular}{|l|l|l|}
\hline \multicolumn{1}{|c|}{+} & \multicolumn{2}{|l|}{ Frequência $>=\mathbf{2 . 8 6}$ / Ordem de evocação $>=3$} \\
\hline \hline $7.14 \%$ & conteúdo & 3.4 \\
\hline \hline $5.71 \%$ & objetivo & 3.75 \\
\hline \hline $4.29 \%$ & articulação & 3.33 \\
\hline \hline $4.29 \%$ & contextualização & 4.33 \\
\hline \hline $2.86 \%$ & discussão & 3 \\
\hline $2.86 \%$ & execução & 3 \\
\hline \hline $2.86 \%$ & debate & 3.5 \\
\hline
\end{tabular}

\begin{tabular}{|l||l||l|}
\hline++ & Frequência $<2.86 /$ Ordem de evocaço $<3$ \\
\hline \hline $1.43 \%$ & elaboração & 1 \\
\hline $1.43 \%$ & aprendizagem & 1 \\
\hline \hline $1.43 \%$ & diversidade & 2 \\
\hline \hline $1.43 \%$ & criatividade & 2 \\
\hline $1.43 \%$ & pergunta & 2 \\
\hline
\end{tabular}

\begin{tabular}{||l||l|l|}
\hline- & \multicolumn{2}{|c|}{ Frequência < 2.86 / Ordem de evocação > $\mathbf{3}$} \\
\hline \hline $1.43 \%$ & estratégias & 3 \\
\hline \hline $1.43 \%$ & conhecimento & 4 \\
\hline $1.43 \%$ & reformulação & 4 \\
\hline \hline $1.43 \%$ & reflexão & 4 \\
\hline \hline $1.43 \%$ & feedback & 5 \\
\hline $1.43 \%$ & análise & 5 \\
\hline \hline $1.43 \%$ & conclusão & 5 \\
\hline
\end{tabular}

Fonte: Elaboração dos Autores

Com base na teoria das representações sociais, este quadro é dividido em quadrantes, sendo que o núcleo central é representado no quadrante ++ , a primeira zona de periferia fica no quadrante +-, a segunda zona de periferia fica no quadrante -+ e a zona de contraste fica no quadrante - -. Para analisarmos 0 que as palavras elencadas pelos licenciandos representam, inserimos o nosso corpus de análise no software IraMuTeQ para que por meio de um gráfico de similitude, conseguíssemos evidenciar as possíveis relações entre as palavras como mostra no lado esquerdo da Figura 5. Como os elementos mais importantes ficam no núcleo central, conforme recomenda Sá (1996), suprimimos as arestas das outras palavras como se evidencia no lado direito da Figura 5. 


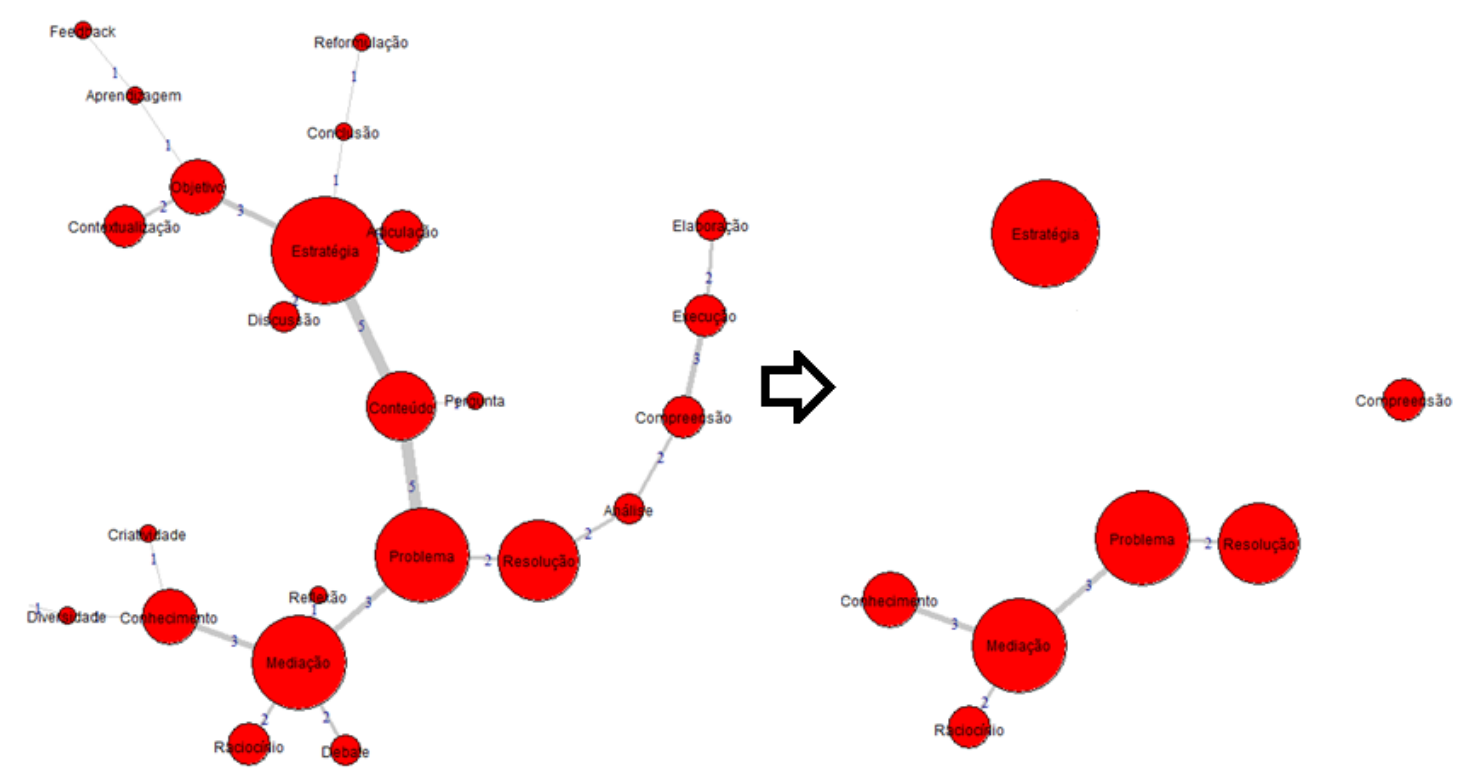

Figura 5: Gráfico de similitude representando as ligações entre as palavras evocadas (Elaboração dos Autores)

É possivel perceber que as palavras do núcleo central também são as contidas nos maiores círculos vermelhos. Além disso, estas são ligadas por traços cinzas que contém a quantidade de ligações que uma palavra faz com outra, sendo que quanto maior a frequência, mais expressiva são as ligações. Assim, podemos analisar cada uma destas palavras e suas ligações com base na representação social dos licenciandos sobre o que eles consideram ser 0 ensino via resolução de problemas com base nas ações de Proença (2018).

A palavra estratégia é a mais representativa para os licenciandos, por ter a maior frequência - Fr $(11,43 \%)$ e a menor ordem de evocação - OE $(2,5)$, em relação à esta frequência. Por este termo ser polissêmico, evidenciamos sua utilização em dois sentidos:

a) Os alunos devem ter estratégias para realizar a resolução do problema: esse entendimento é reforçado pelas falas de E3 - "Após a compreensão o aluno deve pensar nas suas estratégias para resolver o problema" e E18 - "Os alunos devem estar dispostos a desenvolverem diferentes estratégias para resolver o problema".

b) Estratégia do professor para criar o problema: esse entendimento é reforçado pelas seguintes falas: E8 - "É necessário pensar em uma situação que permita ao aluno pensar em diferentes formas de resolver" e E16 - "O pensar de como o aluno resolverá". Percebemos que este entendimento está ligado à primeira ação, a de escolha do problema, conforme ressalta Proença (2018) que: 
[...] o professor deve de antemão conhecer e prever possíveis estratégias de resolução: supor e testar (tentativa e erro), fazer desenhos/figuras, utilizar casos particulares, montar ou encontrar um padrão (processo de generalização), trabalhar no sentido inverso, fazer uma simulação e experimentação, realizar a dedução lógica, ou utilizar qualquer tipo de representação de dados: gráfico, equação, expressão algébrica, diagrama, uma tabela ou quadro (listagem de valores) (p. 47).

Estas estratégias poderão ser tomadas tanto pelo professor como pelo aluno para a resolução. A segunda palavra mais representativa para os licenciandos foi mediação $(\mathrm{Fr}=11,43 \%, \mathrm{OE}=2,75)$. As falas que justificaram a escolha desta palavra estão ligadas à terceira ação de auxílio aos alunos durante a resolução como expressam E10 - "Sem mediação, não é possível saber como os alunos estão caminhando" e E18 - "O professor deve saber mediar sem dar as respostas conduzindo os alunos". Desta forma, compreendemos esta ligação com a terceira ação, pois Proença (2018, p. 51) destaca que o papel do professor é o de "observador, incentivador e direcionador de aprendizagem, apoiando os alunos a desenvolver autonomia frente ao processo de resolução".

Também é possível perceber na Figura 5 que esta palavra tem uma ligação $(n=3)$ com a palavra problema $(\mathrm{Fr}=10 \%, \mathrm{OE}=1,86)$, a terceira do núcleo central. No entanto, percebemos segundo as falas dos estudantes que o termo problema está ligado à primeira ação, a de escolha do problema, como mostram as falas de E10 - "É necessário um bom problema para não limitar os alunos a uma só resolução" e E18 - "O problema deve ser bem elaborado para que a metodologia funcione". Desta forma, vale lembrar que o problema é um dos pontos principais desta abordagem, devendo o professor escolhê-lo de acordo para que realmente se torne um problema aos alunos conforme aponta Ecreverría (1998).

O quarto termo é resolução $(\mathrm{Fr}=7,14 \%, \mathrm{OE}=2,6)$ sendo que apesar de estar atrelado a ideia de resolução de problemas, este termo esteve ligado à terceira ação, a de auxílio aos alunos durante a resolução, como mostra as falas de E1 - "Permite aos alunos utilizar seus conhecimentos anteriores em um novo problema e E2 - "Por em prática o plano elaborado seguindo a resolução de problemas proposta". Percebemos assim, que é o momento em que 0 aluno está desenvolvendo a resolução de problemas. Proença (2019) estipula que neste momento o aluno pode seguir as etapas para a resolução da situação como os definidos por Brito (2006) sendo: a representação, planejamento, realização e monitoramento.

Na Figura 5, observamos ainda que conhecimento ( $\mathrm{Fr}=5,71 \%, \mathrm{OE}=2)$ tem uma ligação $(n=3)$ com mediação. Nesse sentido, percebemos que as representações sociais dos licenciandos 
ligadas à esta palavra estão voltadas para a terceira ação, conforme expressam as falas de E4 "Os alunos deverão ter conhecimento sobre os conteúdos a serem abordados" e E11 — "Utiliza sempre os conhecimentos prévios como ponto de partida". Percebemos, assim, que o conhecimento que os alunos podem obter sobre o conteúdo, advém sobre eles conseguirem utilizar seus conhecimentos prévios para resolver o problema, sendo nesta ação que se desenvolve esse processo. Este entendimento dos alunos está de acordo, conforme recomenda também os PCN.

É possível observar também na Figura 5, que o termo raciocínio $(\mathrm{Fr}=4,29 \%$ e OE $=2)$ também tem uma ligação $(n=2)$ com mediação. Para os licenciandos esta palavra relaciona-se ao raciocínio que o aluno deverá ter para resolver o problema como expressa E11 — "Favorece que os alunos procurem modos para solucionar o problema", sendo importante para isso a mediação do professor e, neste sentido esta palavra também se enquadra na terceira ação de Proença (2018).

Por fim, a palavra compreensão $(\mathrm{Fr}=2,86 \%, \mathrm{OE}=1,5)$, também relacionada à terceira ação, conforme mostra a fala de E1 - "A compreensão deve ser tanto do professor quanto do aluno para que possa ser elaborado as estratégias". Nesse sentido, compreendemos que o professor deve estar alinhado aos alunos na hora de resolverem os problemas para que tenham compreendido corretamente a atividades, mas como destaca Proença (2018), sem fornecer as respostas prontas.

Desta forma, observamos que as principais representações dos licenciandos estiveram ligadas à primeira ação, a escolha do problema, em que o professor deve pensar estratégias para formular/escolher um bom problema. Outrossim, as representações também estão ligadas à terceira ação, a de auxílio aos alunos durante a resolução, em que os alunos devem utilizar suas estratégias para realizar a resolução do problema, e o professor deve ter um papel de mediador, para que os alunos a partir de seu raciocínio, utilizem seus conhecimentos prévios para chegar à uma compreensão/solução do problema.

\section{Considerações}

Com o objetivo de analisar a compreensão de licenciandos em Matemática para abordarem, em sala de aula, o ensino-aprendizagem de Matemática via resolução de problemas, realizamos um curso de formação a partir de aulas teóricas e do desenvolvimento de uma prática 
baseada nas ações propostas por Proença (2018) em uma turma de futuros professores de Matemática, que previamente apresentavam um conhecimento geral sobre o que é trabalhar a resolução de problemas, mas, no entanto, não conheciam essa abordagem de ensino via resolução de problemas, pois indicavam que ela se tratava apenas de um trabalho que utilizava problemas do cotidiano.

Após a realização do curso de formação, os dados de um questionário composto por assertivas do tipo Likert, evidenciaram que a abordagem foi bem recebida pelos licenciandos, uma vez que eles mostraram interesse em utilizá-la no Estágio Curricular Supervisionado. Além disso, foi possível observar que somente um curso de formação não fornece a segurança necessária aos licenciandos para trabalharem com o ensino via resolução de problemas em sala de aula. Desta forma, compreende-se a necessidade de formações contínuas para que possibilitem aos professores um maior entendimento sobre cada uma das ações, devendo-se também realizar a sua implementação na Educação Básica. Contudo, os licenciandos compreenderam a importância da abordagem em que o problema é o ponto de partida, conforme também se identifica no resultado apontado no trabalho de Proença $(2016 \mathrm{~b})$, reafirmando a relevância desta abordagem para o ensino-aprendizagem da Matemática.

Por fim, identificamos que a compreensão dos licenciandos sobre o ensino via resolução de problemas mostrou que, para eles, foi marcante a primeira ação, a de escolha do problema, em que se deve escolher um problema com cuidado e que possibilite ser abordado com várias estratégias. Desta forma, nosso estudo destaca a notoriedade da abordagem descrita por Proença (2018) ao avançar no quesito da escolha do problema, momento chave da resolução de problemas e considerado de maior dificuldade nos trabalhos de Raiva, Moraes e Borges (2015) e Proença (2016a). Da mesma forma, também foi expressivo a terceira ação, a de auxílio dos alunos durante a resolução, sendo o professor um mediador para levar os alunos a raciocinarem, utilizando-se de seus conhecimentos prévios para chegar à solução.

\section{Referências}

ABRIC, Jean-Claude. A abordagem estrutural das Representações Sociais. In: MOREIRA, Antonia Silva Paredes; OLIVEIRA, Denise Cristina. (Org). Estudos interdisciplinares de Representação Social. Goiânia: Cultura e Qualidade, 2000, p. 27-39.

ALLEVATO, Norma Suely Gomes; ONUCHIC, Lourdes de La Rosa. Ensino-AprendizagemAvaliação de Matemática: por que através da Resolução de Problemas? In: ONUCHIC, Lourdes 
de La Rosa; ALLEVATO, Norma Suely Gomes; NOGUTI, Fabiane Cristiane Höber; JUSTULIN, Andressa Maria. (Org.). Resolução de Problemas: teoria e prática. Jundiaí: Paco, 2014, p. 35-52.

BRASIL. Ministério da Educação. Secretaria de Educação Básica. Base Nacional Comum Curricular. Ensino Médio. Brasília: MEC/SEB, 2018.

BRASIL. Ministério da Educação. Secretaria de Educação Básica. Base Nacional Comum Curricular: Educação Infantil e Ensino Fundamental. Brasília: MEC/SEB, 2017.

BRASIL. Ministério da Educação. Secretaria de Educação Fundamental. Parâmetros Curriculares Nacionais: Matemática. Brasília: MEC/SEF, 1998.

BRITO, Márcia Regina Ferreira de. Alguns aspectos teóricos e conceituais da solução de problemas matemáticos. In: BRITO, Márcia Regina Ferreira de. (Org.). Solução de problemas e a Matemática escolar. 2. ed. Campinas: Alínea, 2010, p. 13-53.

ECHEVERRÍA, María del Puy Pérez. A solução de problemas em Matemática. In: POZO, Juan Ignacio (Org.). A solução de problemas: aprender a resolver, resolver para aprender. Tradução de Beatriz Affonso Neves. Porto Alegre: ArtMed, 1998, p. 43-65.

FIORENTINI, Dario. Formação de professores a partir da vivência e da análise de práticas exploratório-investigativas e problematizadoras de ensinar e aprender Matemática. In: XIII CONFERÊNCIA INTERAMERICANA DE EDUCAÇÃO MATEMÁTICA, 2011, Recife. Anais da XIII CIAEM. Recife: UFPE, 2011, p. 1-14.

GIL, Antonio Carlos. Métodos e técnicas de pesquisa social. 6.ed. São Paulo: Atlas, 2008.

JODELET, Denise. Representaciones sociales: contribucion a un saber sociocultural sin fronteras. Revista Educação e Cultura Contemporânea, Rio de Janeiro, v.1, n. 2, p. 23-38, jul./dez. 2004.

MAYER, Richard Edward. Thinking, problem solving, cognition. 2. ed. New York: WH Freeman and Company, 1992.

MOÇO, Priscila Pedroso. Discussões sobre a resolução de problemas enquanto estratégia metodológica para o ensino de Matemática. 2013. 114f. Dissertação (Mestrado em Educação em Ciências) - Centro de Educação Ambiental, Ensino de Ciências e Matemática. Universidade Federal do Rio Grande. Rio Grande.

PARANÁ. Secretaria de Estado da Educação. Superintendência da Educação. Diretrizes Curriculares de Matemática para a Educação Básica. Curitiba: SEED, 2008.

POLYA, George. A arte de resolver problemas: um novo enfoque do método matemático. 2 ed. Tradução de Heitor Lisboa de Araújo. Rio de Janeiro: Interciência, 1994.

PROENÇA, Marcelo Carlos de. A compreensão de licenciandos em Matemática sobre o ensino via resolução de problemas: análise por meio de uma proposta de formação. Boletim GEPEM, Rio de Janeiro, n. 68, p. 19-35, jan./jun. 2016b.

PROENÇA, Marcelo Carlos de. Favorecendo a compreensão do ensino por meio da resolução de problemas: experiência da Prática como Componente Curricular. Educação Matemática em 
Revista, Brasília, v. 21, n. 49B, p. 52-60, 2016a.

PROENÇA, Marcelo Carlos de. Resolução de Problemas: encaminhamentos para o ensino e a aprendizagem de Matemática em sala de aula. Maringá: EdUEM, 2018.

PROENÇA, Marcelo Carlos de. Uma proposta de ensino-aprendizagem das operações aritméticas com frações via resolução de problemas. Educação Matemática em Revista, Brasília, v. 24, n. 63, p. 5-17, jul./set. 2019.

RAIVA, Vladimir Nassone Pedro. MORAES, Marcos Evandro Lisboa de. GUERRA, Renato Borges. Resolução de problemas na formação do professor de Matemática: desafios e possibilidades. In: XIV CONFERÊNCIA INTERAMERICANA DE EDUCAÇÃO MATEMÁTICA, 2015, Chiapas. Anais da XIV CIAEM. México, 2015, p. 1-12.

SÁ, Celso Pereira. Núcleo das Representações Sociais. 2. ed. revista. Petrópolis: Vozes, 1996.

SCHROEDER, Thomas L.; LESTER JR, Frank K. Developing understanding in Mathematics via problem solving. In: TRAFTON, Paul R.; SHULTE, Albert P. (Org.). New directions for elementary school mathematics. Reston: NCTM, 1989, p. 31-42.

SERRAZINA, Lurdes. Resolução de Problemas e a Formação de Professores: um olhar sobre a situação em Portugal. In: ONUCHIC, Lourdes de la Rosa; JUNIOR LEAL, Luiz Carlos; PIRONEL, Márcio (Org.). Perspectivas para Resolução de Problemas. São Paulo: Livraria da Física, 2017, p. $55-83$

SOUZA, Kellcia Rezende; KERBAUY, Maria Teresa Miceli. Abordagem quanti-qualitativa: superação da dicotomia quantitativa-qualitativa na pesquisa em Educação. Revista Educação e Filosofia, Uberlândia, v. 31, n. 61, p. 21-44, jan./abr. 2017.

STERNBERG, Robert. J. Psicologia cognitiva. Tradução de Maria Regina Borges Osório. Porto Alegre: ArtMed, 2000.

VALE, Isabel. Resolução de Problemas um tema em contínua discussão: vantagens das resoluções visuais. In: ONUCHIC, Lourdes de la Rosa; JUNIOR LEAL, Luiz Carlos; PIRONEL, Márcio (Org.). Perspectivas para Resolução de Problemas. São Paulo: Livraria da Física, 2017, p. 131-162. 